\title{
MANAGEMENT OF CHILDREN WITH CLEFT LIP AND PALATE: A REVIEW DESCRIBING THE APPLICATION OF MULTIDISCIPLINARY TEAM WORKING IN THIS CONDITION BASED UPON THE EXPERIENCES OF A REGIONAL CLEFT LIP AND PALATE CENTRE IN THE UNITED KINGDOM
}

PETER D HODGKINSON, SUSAN BROWN, DOROTHY DUNCAN, CHRISTINE GRANT, AMY MCNAUGHTON, POLLY THOMAS AND C RYE MATTICK

Northern and Yorkshire Cleft Lip and Palate Service, Ist Floor Doctors Residence, Royal Victoria Infirmary, Queen Victoria Road, Newcastle upon Tyne NEI 4LP.

\section{INTRODUCTION}

The management of children with cleft lip and palate presents many challenges but also many rewards. Our involvement with these children and their families often begins before birth and can extend into late adulthood. Affected individuals present a multiplicity of problems and effective management involves a wide range of specialists.

The currently accepted model for delivery of this care in the most appropriate way is the multidisciplinary cleft team. This is a group of individuals from different specialist backgrounds who work closely together, not only to bring each specialist's particular expertise to the patient in the optimum way, but also to develop an understanding of the requirements and specialist skills of the other team members to enhance the delivery of the total package. It has been suggested that such an integrated system of delivery of care enables the individuals within the team to function in an interdisciplinary way so that all aspects of health care for the cleft condition can be delivered in as seamless a way as possible.

This model has an international acceptance and many centres have slowly developed their services along these lines. However, within the United Kingdom there has been a period of more rapid change stimulated by a government report $\left(\mathrm{CSAG}^{1}\right)$ leading to a major reorganisation of cleft services across England and Wales particularly. This report and its consequences are discussed later.

Address for correspondence: Peter D Hodgkinson, Consultant Plastic Surgeon, Royal Victoria Infirmary, Newcastle upon Tyne NE1 4LP. 
It is understood that the antenatal diagnosis of clefts involving the lip is relatively straightforward for an experienced sonographer whereas identification of clefts involving the palate is much more difficult. The needs of children with clefts involving the palate, whether or not the lip is involved, are similar and we shall discuss all types of common labiopalatine clefting.

This review is written by and based upon the experiences of the individual specialists working at the Newcastle site of the Northern and Yorkshire Cleft Lip and Palate Service. It is based upon our current working practices and we have endeavoured to illustrate how this represents current best practice and the evidence to support this where possible.

\section{PREVALENCE}

Non-syndromic cleft lip and palate is reported to occur in approximately 1 in 700 live births, with the prevalence varying according to parental race/ethnicity and geographic origin, infant sex and the family's socio-economic status ${ }^{2}$. True prevalence is not known because fetuses with malformations are more likely to be spontaneously aborted than healthy fetuses and, although the risk of cleft lip and palate is three times higher in stillbirths than live births ${ }^{3}$, most studies only report the prevalence of clefts in live births. Therefore the prevalence of cleft lip and palate is likely to be under-reported. The UK survey of cleft care by the Clinical Standards Advisory Group $^{1}$ suggested that poor documentation would exaggerate under-reporting. This study found that the number of reported cases of cleft lip and/or cleft palate in England and Wales was 1:1054 live births (630 live births with clefts in 1995) and had fallen as compared with 1:930 live births in 1990. The UK reported reduction in incidence is at odds with other areas of Europe who report an increase ${ }^{4}$. This international increase has been attributed to better documentation, decreased neonatal mortality and the increased frequency of marriage of patients with clefts as a consequence of better care.

The reported prevalence of the different types of cleft lip and palate (CLP) varies. Cleft lip with cleft palate is the most common presentation in most racial groups. The relative prevalence of cleft lip alone varies however, both within and between different racial groups. In Denmark the reported prevalence is 1:2:1 of cleft lip:cleft lip and palate:cleft palate respectively ${ }^{5}$. In Northern Ireland, clefts are distributed as follows; secondary palate only $(53 \%)$, primary palate only $(16 \%)$, both $(26 \%)$ and unrecorded $(5 \%)$. More males than females were affected, and more males had complete clefts. Unilateral clefts were most common on the left hand side ${ }^{6}$. Few prevalence studies discriminate between unilateral CLP and bilateral CLP, although a prevalence ratio of 4:1 has been reported. ${ }^{4}$

The aetiology of cleft lip and/or palate is still largely unknown. The majority of clefts of the lip and palate are believed to have a multifactorial aetiology with several genetic and environmental factors interacting to shift the complex process 
Table I Some of the more common syndromes associated with cleft lip and palate

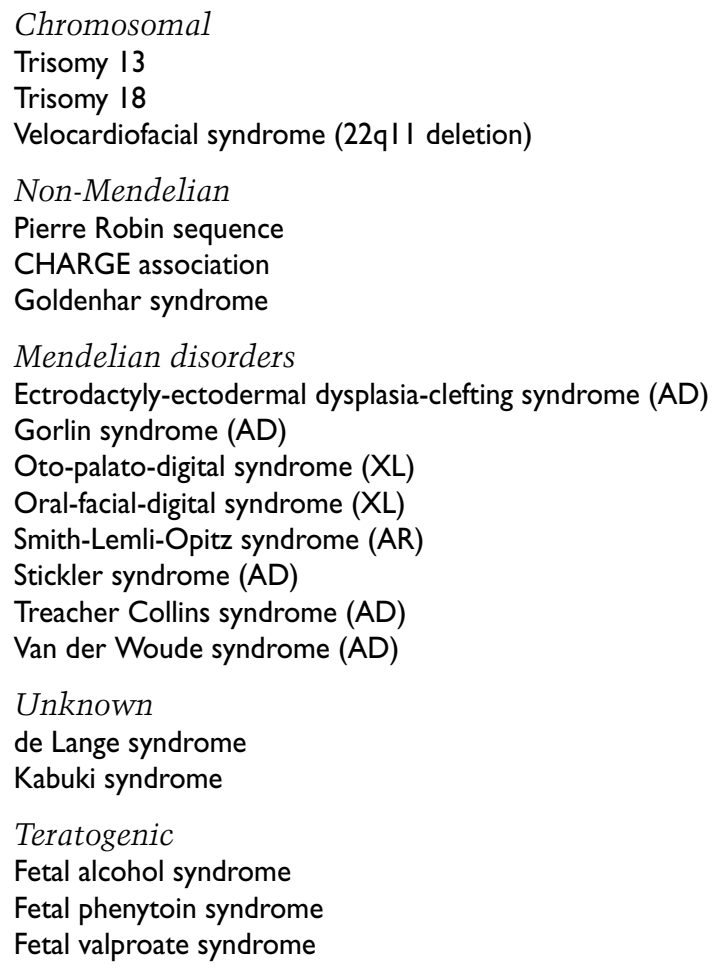

of morphogenesis of the primary and secondary palates toward a threshold of abnormality at which clefting can occur ${ }^{7}$.

\section{ASSOCIATED ANOMALIES}

Patients with oral clefts may also exhibit other anomalies, although the published data varies significantly between studies. Recent research would indicate that $21-37 \%$ of patients might have other anomalies including: cardiovascular (24-51\%), musculoskeletal, facial dysmorphia or genitourinary system disturbance ${ }^{8,9}$. Children with associated anomalies are more likely to have combined CLP or cleft palate, rather than cleft lip alone ${ }^{8}$. They are often of lower birth weight ${ }^{10}$.

There are over 400 syndromes which include cleft lip and/or cleft palate as a component listed in the London Dysmorphology Database. Some of the more common syndromes are listed in Table $1^{11}$. 
Even after the exclusion of people with additional anomalies and within a well controlled population, it has been found recently that patients with CLP have increased mortality up to the age of 55 compared with the non-cleft population (Christensen $\left.{ }^{12}\right)$.

\section{EMBRYOLOGY OF CLEFT LIP AND PALATE}

The development of the face and upper lip occurs between the fifth and ninth weeks of pregnancy. The larger medial and smaller lateral nasal processes develop on either side of the frontonasal prominence as the nasal placodes deepen. The medial nasal processes grow larger and approach each other in the midline. The maxillary processes develop as cephalic outgrowths from the mandibular process or first branchial arch. The maxillary processes grow forward and medially below the lateral nasal processes. They continue to grow medially merging with the medial nasal processes and then growing over them to meet in the midline. The face is fully formed by the eighth week.

The facial processes consist of an epithelial surface with a mesenchymal core. It is believed that epithelial fusion is followed by mesenchymal penetration of the fused processes. Failure of these processes may cause a cleft lip.

Thus:-

1 The lip is formed by the fused maxillary processes.

2 The premaxilla - palate in front of the incisive foramen and the alveolus between the canines - is formed from the frontonasal process.

3 Clefts of the lip become more severe from front to back, i.e. from the vermillion margin of the lip upwards towards the nose and backwards to involve the alveolus.

4 Simonart's bands are narrow bridges of skin and mucosa that cross otherwise complete clefts of the lip and alveolus. This can lead to the appearance of an apparently less severe lip cleft with a more severe, usually complete, alveolar cleft behind it.

5 The lip and premaxilla are often referred to as the primary palate.

Palatal development occurs between the sixth and eleventh weeks. Palatal shelves grow out from the inner aspect of the maxillary processes. At first they hang vertically downwards with the tongue in between. As the neck begins to extend between the eighth and ninth week, the tongue moves down. The palatal shelves become horizontal by an active process involving intrinsic changes in tension within the shelves that can overcome the force of the tongue. Once elevated the palatal shelves fuse with the primary palate anteriorly and with each other more posteriorly. Fusion of the palatal shelves occurs from front to back and is a process of epithelial adhesion and fusion followed by epithelial seam disintegration and mesenchymal in-growth.

Thus:-

1 The palate is formed from the palatal processes of the maxillary processes.

2 Clefts of the palate become more severe from back to front. 


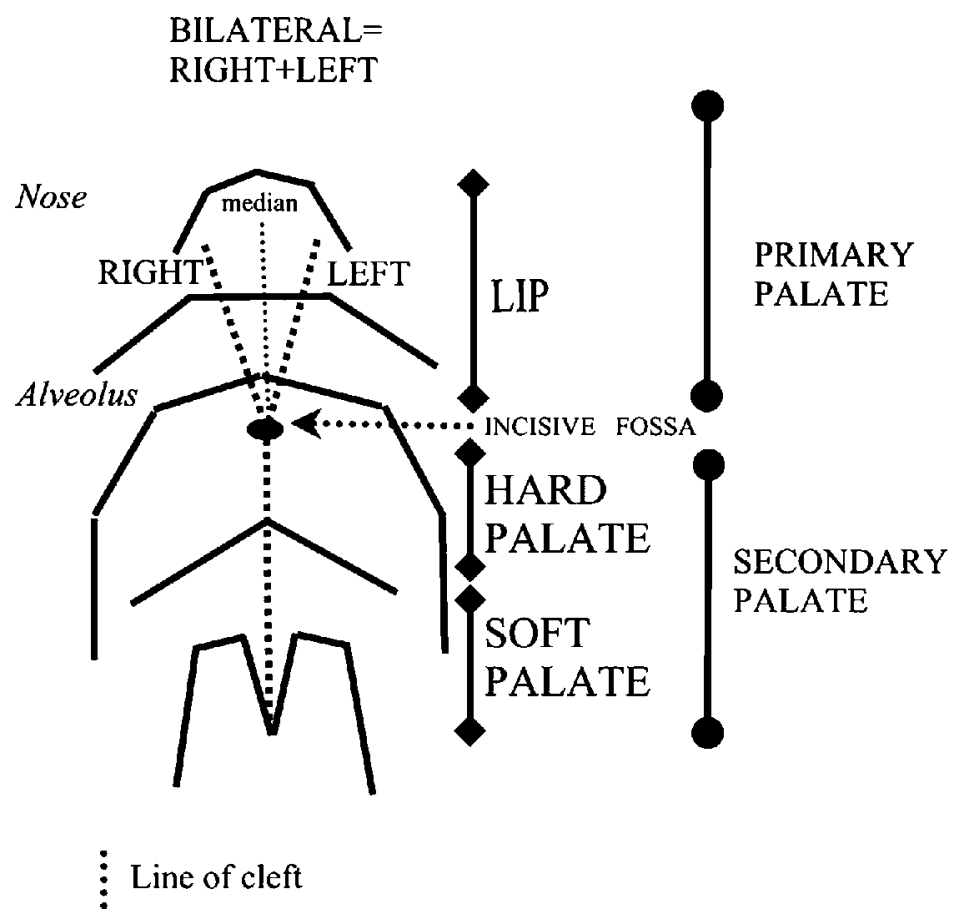

Figure I Schematic representation of the lip and palate to explain the classification systems.

3 Classically it has been assumed that a palatal cleft in association with a lip cleft results in some way from the presence of the lip cleft and the distortions or abnormalities within the primitive upper jaw that have arisen because of the lip cleft. This simplistic explanation does not entirely explain those clefts of the soft palate that occur in cases of cleft lip when the alveolus and hard palate are intact and it is more likely that more generalised failures of epithelial fusion and mesenchymal consolidation may be to blame.

4 Submucous clefts of the palate probably represent inadequacy of mesenchymal ingrowth following epithelial fusion of the palate and classically present with a bifid uvula, notch at the back of the hard palate and a lucent line along the palate with misalignment of the palatal muscles.

5 The hard and soft palates together are sometimes referred to as the secondary palate.

\section{CLASSIFICATION OF THE DIFFERENT TYPES OF CLEFT LIP AND/OR CLEFT PALATE}

In some way each patient with a cleft of the lip and/or palate is different from every other. However, it is important to classify patients into groups for management and study purposes. Most classifications in common usage are based upon the processes of facial embryology and follow in a more or less detailed way the schematic shown in Figure 1. 

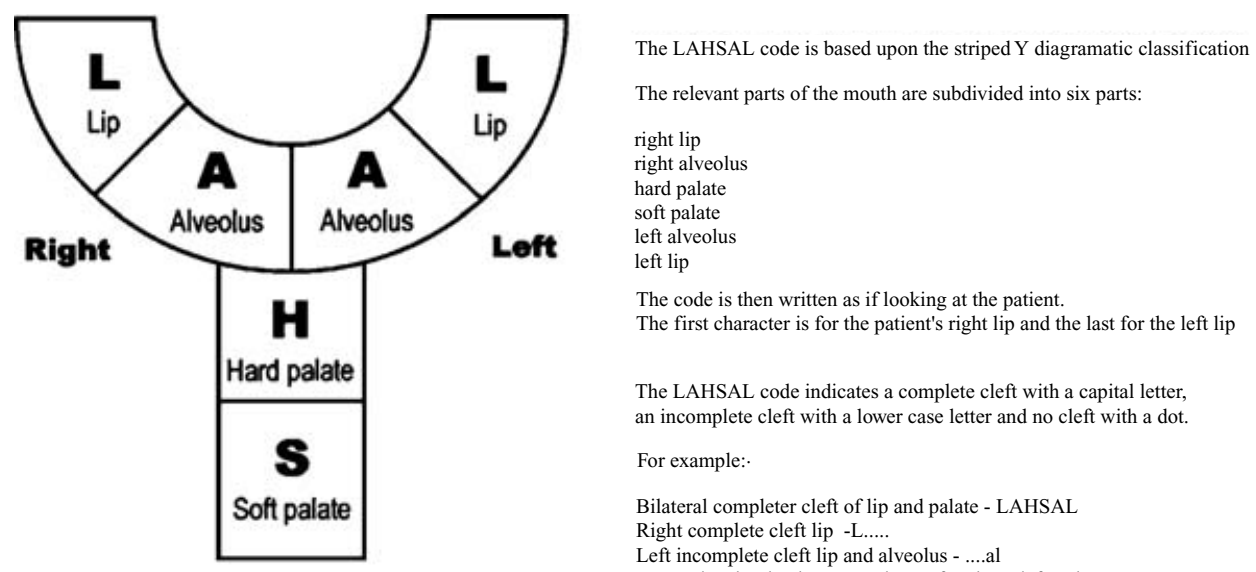

The code is then written as if looking at the patient.

The first character is for the patient's right lip and the last for the left lip

The LAHSAL code indicates a complete cleft with a capital letter, an incomplete cleft with a lower case letter and no cleft with a dot. For example:

Bilateral completer cleft of lip and palate - LAHSAL

Right complete cleft lip -L....

Left incomplete cleft lip and alveolus - ....al

Incomplete hard palate, complete soft palate cleft - ..hs.

Figure 2 LAHSAL system for the classification of cleft lip and/or palate.
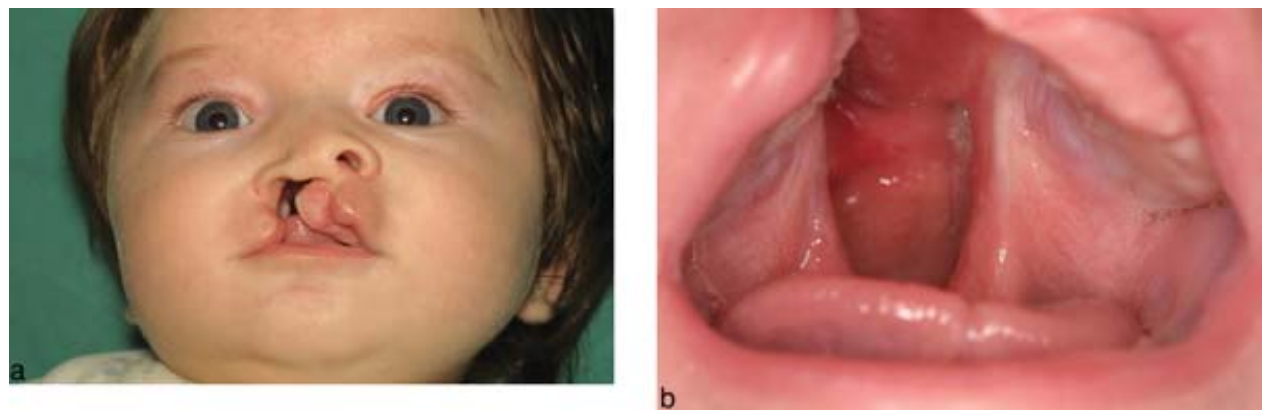

Figure 3 Complete unilateral cleft of the lip and palate.

Some symbolic methods have been used, of which the Striped Y of Kernahan ${ }^{13}$ is perhaps the most common example. In the UK, there has been a general move to adopt a simple system, which is easy to use yet has sufficient accuracy for most purposes. It is based on the LAHSHAL system devised by Otto Kreins, modified on the recommendation of the Royal College of Surgeons ${ }^{14}$ by omitting one " $\mathrm{H}^{\prime}$ (this removes the scope to record bilateral clefts of the hard palate, but results in a far simpler system). It is compatible with ICD 10 and allows clefts to be coded for computer use, most importantly on the Craniofacial Anomalies Register which has the aim of recording every cleft patient in Britain (Figure 2).

Some examples of different types of lip and palate clefts are illustrated in Figures 3-6. From experience, it is possible to make some general statements about different types of cleft.

1 In unilateral cases the width of the lip cleft is governed by the muscular pull of orbicularis oris, the fibres of which are inserted into the anterior nasal spine medially and side of the nose, pyriform margin and cleft margin laterally. The cleft 

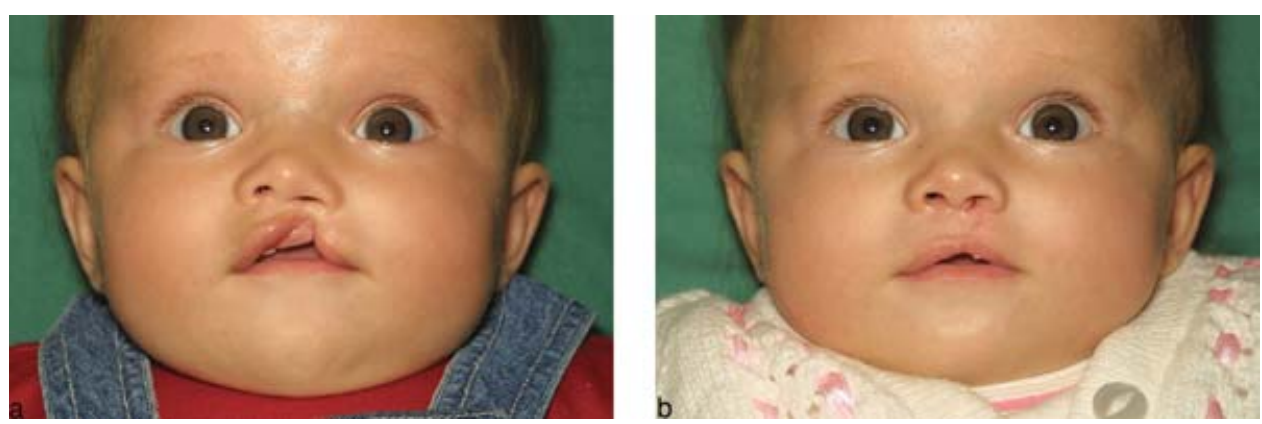

Figure 4 Incomplete unilateral cleft lip - pre- and post-op views.
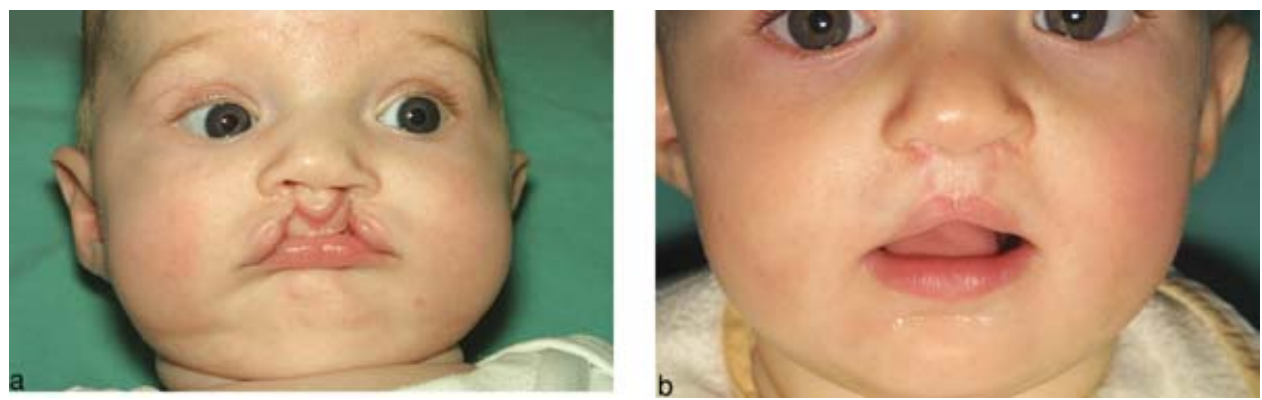

Figure 5 Bilateral cleft lip and palate - pre- and post-op views.

is stabilised by an intact alveolar ridge and/or hard palate. In general therefore the lip cleft and nasal distortion tend to be more severe when the palate is also cleft, although wide lip clefts may be seen even if the palate and more rarely the alveolar ridge are intact. However, usually if the palate is intact a less severe cleft and less distorted nose results - Figure 4.

2 All components of the lip are assumed to be present although distorted to a greater or lesser extent. Often some elements of the lip, particularly on the cleft side, appear smaller than the contralateral side.

3 In a wide unilateral cleft of the lip it can appear that a segment of the lip below the nose is missing completely when this is not the case. This is a relatively frequently reported antenatal ultrasound finding. This is illustrated in Figures 3 and 8 in two babies with the lip elements pulled away to either side but all present.

4 Similarly a wide unilateral lip cleft may appear to be in the midline - a median cleft. Median clefts are rare and associated with midline brain defects until proven otherwise. Typically median clefts distort the columella and central part of the nose, not the nostrils themselves.

5 In complete bilateral clefts the premaxilla and prolabial segment rotate up under the nose and may appear to be missing in some views.

6 Rare craniofacial clefts may involve the lip but extend up alongside the nose rather than into the nostrils (Figure 7). 


\section{8}

Peter Hodgkinson et al.

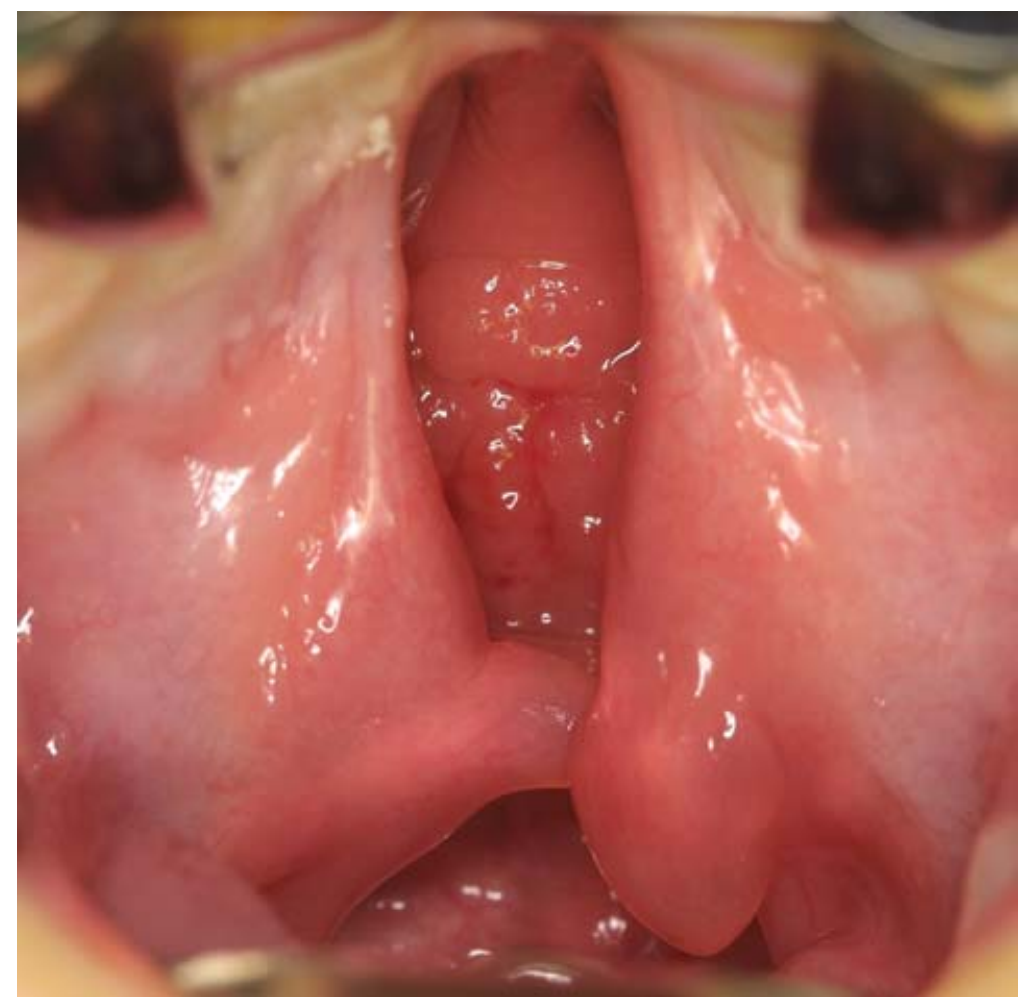

Figure 6 Cleft of the palate only.
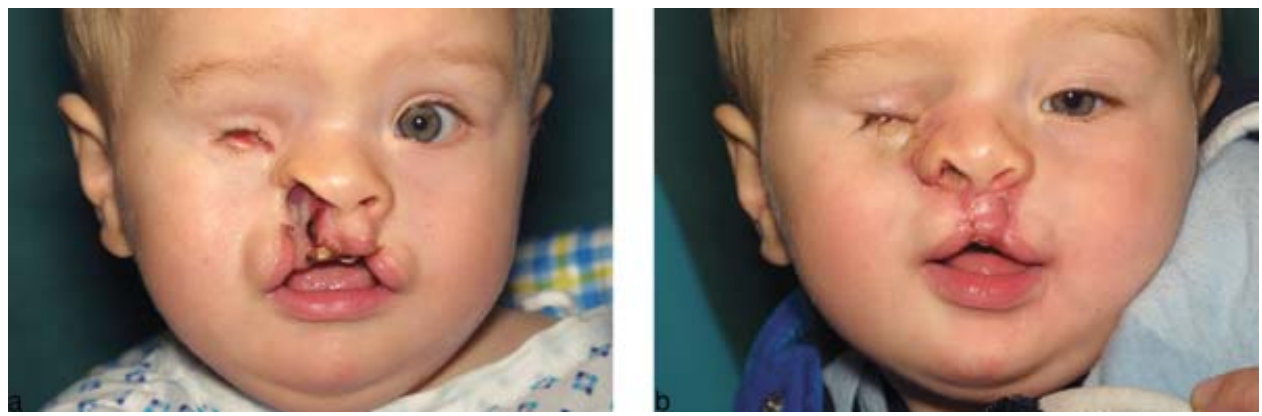

Figure 7 Complex craniofacial cleft - pre- and post-op.

\section{CARE OF THE PATIENT WITH CLEFT LIP AND PALATE}

Care of the patient within a multidisciplinary team requires the development of a protocol of care or care pathway to enable the team members to function most effectively and to maximise the benefits of this system to the patient. 
Table 2 Outline Care Pathway for children with cleft lip and/or cleft palate

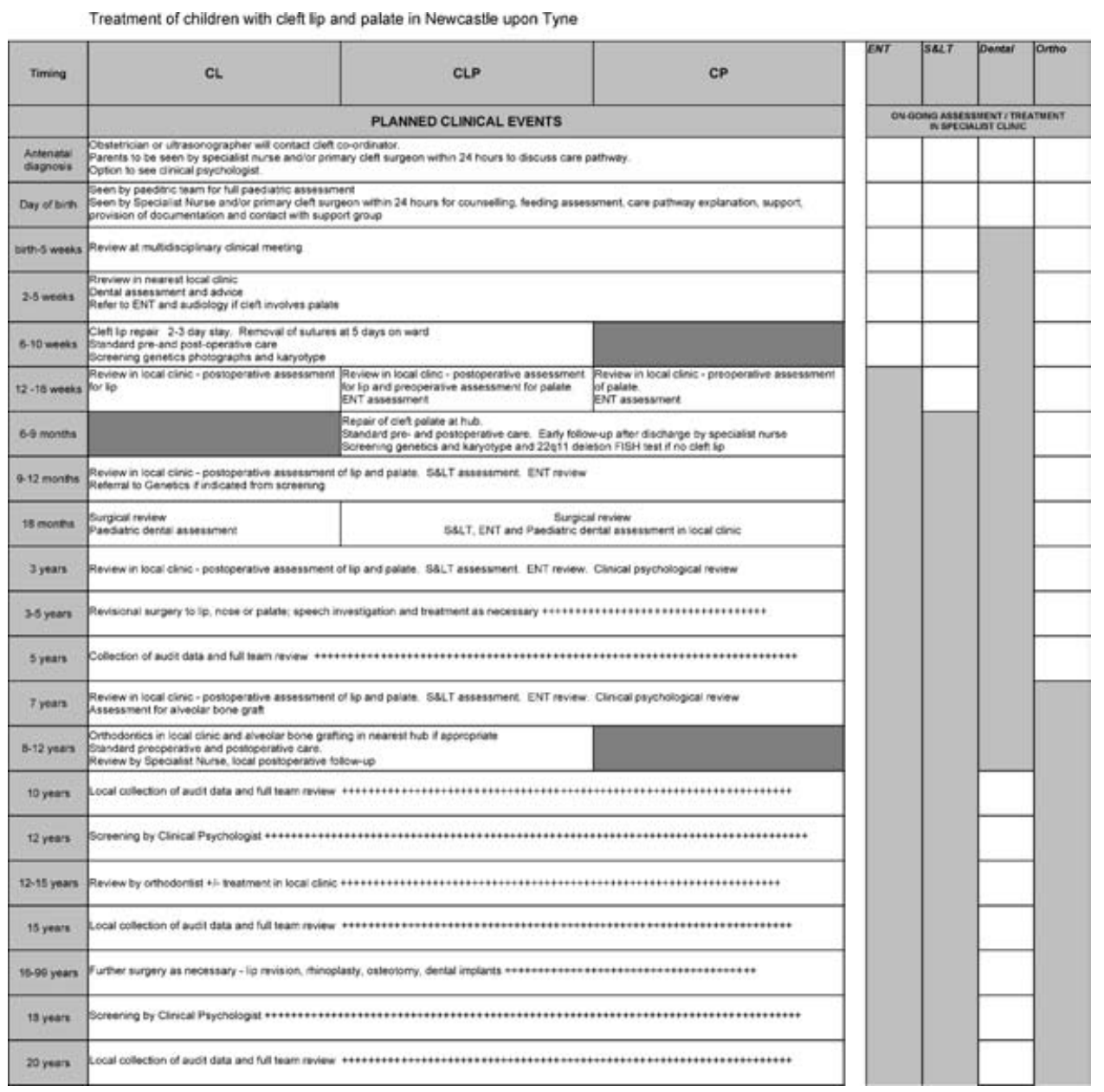

Abbreviations: CL, cleft lip; CLP, cleft lip and palate; CP, cleft palate; ENT, Ear, Nose and Throat; S \& LT, Speech and Language Therapy; Ortho, Orthodontics.

An outline of the treatment pathway adopted by the Northern and Yorkshire cleft service is shown in Table 2.

This outline of care begins with antenatal diagnosis and continues to adulthood. The patient may be under active treatment by several members of the team at once. Sometime this occurs at the same time and place in multidisciplinary clinics. At other times specialist treatment, for example speech and language therapy, ENT or psychological treatment, is provided in a separate environment.

The components of the treatment of the cleft patient are described below in approximately chronological order. 


\section{Antenatal diagnosis}

Improvements in ultrasound scanning have resulted in antenatal diagnosis of clefts becoming more common. As soon as possible after diagnosis the referral should be made to the regional CLP team. If patients have been told and want to know more information, it is imperative that telephone contact be made with the cleft team before they leave the scanning department so that arrangements can be made for the specialist nurse to visit at the earliest opportunity. A report by Jones ${ }^{15}$ found that parents who had a delay in obtaining information turned to the Internet. This has been found to cause parents more anxieties, as some of the information they download is inaccurate. It is our protocol to make contact with these families within 24 hours.

Parents are often very shocked when they learn their child has a facial disfigurement. They need reassurance, support and time to assimilate the information. An accurate diagnosis is critical to the process of counselling families; the responsibility of the referral centre is to define the nature of the structural defect with as much precision as possible. This helps the family to visualise the child and to discuss feeding, especially breast-feeding. It also helps when informing about timing and type of surgery. To plan for the future, parents need to discuss the management and likely treatment pathway at their own pace and at their own time, so that they are able to absorb the information.

Parents experience varying degrees of shock, anger, denial, distress and anxiety. Many parents express a feeling of loss of control - despite their plans for a 'healthy' pregnancy they have been unable to control the outcome. Mothers especially may feel intense guilt as they feel their bodies are the custodians and nurturers of their unborn child ${ }^{16}$. Questions about what have they done or not done during pregnancy are frequently asked. All parents will therefore need help in understanding these confused emotions. The way in which the specialist nurse cares for and supports the mother can aid parents in adjusting to the situation. There needs to be empathy, acceptance, honesty and a non-judgmental approach.

Prenatal diagnosis gives parents the advantage of having time to prepare emotionally for the birth and become knowledgeable about the birth defect. Photographs of children with CLP shown to parents before and after surgery are often invaluable. However it is important that they are shown pictures similar to the diagnosis of the cleft of their child.

During pregnancy, families are given the opportunity to meet with the cleft team at a local clinic. Introduction to a parent support group such as CLAPA /Cleft Lip and Palate Association) and meeting parents of a child with a similar cleft who has undergone surgery may also be helpful. However matching families is difficult and should be done with extreme care. Compatibility of the condition, coping styles and timing should be the main considerations when selecting parents, and the introductions should be arranged at the request of the new parents with preparation of the "mentor" family.

We believe that there is an important supportive role for other parents provided they are carefully selected and monitored, but that professionals should give information 
about a specific cleft and provide any counselling. As well as providing expert care, information, advice and support, the specialist nurses should also act as advocates for the parents. They liaise with other hospitals, the community and all professionals who will be involved with the child's care. A meeting is arranged with the primary care team prior to the birth of the baby. This meeting is attended by the community midwife and health visitor who, with the parents and specialist nurse, plan the initial management in the postnatal period.

With progress in antenatal scanning, cleft lip is often diagnosed before birth, yet of approximately 572 babies born each year with either cleft lip, cleft palate or both, at least $20 \%$ are undiagnosed ${ }^{17}$.

All these feelings of shock, hurt, helplessness and disappointment that have been explored antenatally are often magnified at the birth of an undiagnosed cleft baby. Despite these different reactions it is essential that the parents see the child immediately and are offered a simple explanation. Shielding parents from seeing the baby creates frustration. Martin ${ }^{18}$ concurs with this and stresses that misinformation at the time of birth may be devastating, leading to parents carrying an impression with them for a long time after.

A protocol implemented across all units within the Northern and Yorkshire cleft team referring all babies born with cleft lip and/or palate at birth has improved accessibility. This ensures that all babies are visited by the specialist nurse within 24 hours of referral. This supports the CSAG study ${ }^{1}$ which identified that parents felt that maternity units lacked expertise in the cleft field. However, it is difficult for staff to gain experience and expertise when they may only see 3 to 4 patients a year in local units. It is the role of the specialist nurse to ensure effective communication with all maternity units and establish good links. Teaching packages and teaching sessions are being provided with maternity units now incorporating sessions from the specialist nurse into their own staff development programmes. This will ensure all staff have up to date knowledge of looking after cleft babies and an understanding of the problems parents encounter especially with feeding.

\section{Psychological care}

The psychological care of the patient with a cleft begins at the time of diagnosis, even if this is before birth. With more involvement of specialist psychologists within cleft teams the importance of this is becoming increasingly apparent.

\section{Psychosocial adjustment}

Western society is very focused on the aesthetics of the human body. Those people who are objectively rated as beautiful or attractive are more frequently attributed with personal qualities such as intelligence and trustworthiness ${ }^{19}$. People with facial disfigurements who do not meet idealised standards of attractiveness are more likely to be stigmatised socially ${ }^{20}$. It has been assumed that as a consequence of this process 
the more severe a person's disfigurement, the poorer their psychosocial adjustment will be. However, recent literature has challenged this assumption and many people born with a cleft lip and/or palate will demonstrate psychosocial adjustment within the normative range ${ }^{21,22}$. Despite a substantial number of studies over the past twenty years there remains a lack of clarity about what distinguishes those who adapt well from those who do not. Although the aetiology of adaptation is unclear, there is a general consensus that a sub-group of people with clefts are more anxious, more socially withdrawn, are at higher risk of suicide, have fewer friends and have fewer social contacts ${ }^{23,24}$.

\section{Lifespan perspective}

Taking a lifespan perspective, the earliest interventions that may help to improve social competence and reduce distress begin in the antenatal or perinatal stages of care when working with parents and significant family members. The next stage of opportunities for interventions arises as the child begins to function within the family and within external systems such as school and peer groups. As the child matures and faces the task of individuation from the family there may be a need for psychological work. Lastly, adulthood provides its own set of challenges to the individual and there is potential for further psychological interventions throughout this period of life.

While some of the psychological needs of patients and their families will require the knowledge and expertise of a clinical psychologist, many needs can be met by ensuring psychological thinking and planning takes place at all levels of care.

\section{Nurturing the parents of a newborn with a cleft}

The nature and quality of the attachment a baby forms with their main caregiver is considered to be a highly significant factor in their subsequent ability to relate to others ${ }^{25}$. Factors that can present as a risk to this early relationship are maternal depression ${ }^{26}$, lack of parental social support ${ }^{27}$, bereavement ${ }^{28}$ and infant temperament ${ }^{29}$.

Although there has been an assumption that parents find it harder to bond with a baby with a facial disfigurement ${ }^{30,31}$, there is growing evidence that babies born with a cleft are not at particular risk of developing an insecure attachment ${ }^{32,33}$. Indeed, forming a secure attachment to the parent may be one of the factors that helps buffer the child with a cleft. Hence it is the role of the CLP team to try to facilitate secure infant attachments.

The way that we attempt to do this is to guide parents through a number of stages or tasks:

1 To acquire knowledge and understanding of clefting. For example, to ensure parents understand that in many cases the cause of clefting is as yet unknown. This 
is particularly important for parents who worry a great deal about whether they have somehow caused the cleft to occur; such as, in the case of a parent who has consumed a very small amount of alcohol during their pregnancy and is worried that this has caused the cleft.

2 To encourage the development of parental confidence and skills in handling and feeding which reduces parental anxiety, increases their sense of competency and controllability.

3 To enable the identification and expression of parental emotional reactions. Many parents fantasise about their unborn baby and how the baby's future will be. When they find out that their baby is not as they imagined, they can experience feelings common to other experiences of loss. These are typically, disbelief, numbness, shock, and immense sadness. Hearing that these reactions are common can help to prevent the parent feeling guilty about having reacted in this way.

4 To reduce anxiety about both short and longer term issues and instil a sense of hope and optimism about the baby's future, e.g. worries about the child's future peer relationships and social status.

5 To encourage parents to seek social support, e.g. having access to other parents who have been through some of the same stages they have ahead of them. Also to encourage parents to access voluntary sector support services such as the Cleft Lip and Palate Association (CLAPA).

The speed and ease with which these tasks can be achieved are dependent on individual differences such as parental resources, coping styles and strategies, social support, experience of clefting, history of bereavement and loss, the quality of the parents' own parenting and attachment history, beliefs about causation and responsibility, and co-morbidities in the baby.

The way that parents find out about their baby's cleft lip and/or palate is one of the many factors that will potentially have an impact on the baby's attachment to their parents. In some cases a cleft will have been diagnosed antenatally. In other cases the cleft will be identified by a professional immediately after birth. The Newcastle cleft team's experience suggests that for some parents the disclosure of the baby's cleft has been carefully and sensitively managed by professionals. In these cases the parents' attention had been drawn to the cleft without conveying professional anxiety; questions raised by the parents about why the cleft had occurred were answered in a way that was consistent with later answers to the same questions; parents' needs for information led the pace and level of information supplied; the emotional reactions of parents were accepted by the professional whether the reactions were of grief, shock, disbelief, numbness, anxiety or whether the reactions were of joy, delight, and pride.

Cases where the disclosure was not handled well are examples of the baby's mouth being hidden by a blanket; parents perceiving negative feelings from the professional; providing too much information too quickly and in some cases a lack of knowledge or confidence by the professional providing information about the cleft and subsequent management. 
These findings are supported by an American study ${ }^{34}$. Parents of babies born with clefts were interviewed about their experiences of 'being told the news'. In many cases the disclosures were positive experiences. However, parents wanted more opportunity to talk, more chance to show their feelings, offers of more information about the cleft and the possibilities of the baby having a developmental delay. Of the disclosing professional, the parents wanted them to show more caring and confidence and referral to other parents who had a baby with a cleft.

In cases where the cleft has not been diagnosed at birth or soon after, as is more often the case with clefts of the palate, the baby's struggle to feed causes distress for both parent and baby. Parents may feel inadequate as they struggle unsuccessfully to meet the nutritional needs of the baby; their feeling of loss might be intensified by worrying that they have missed out on the early bonding; they can lose confidence in professionals and begin to worry what else might be wrong that may also have been 'missed'.

\section{Feeding the new-born cleft infant}

The specialist cleft nurses in our team are the first members of the cleft service to meet the new baby and its parents. One of the main concerns of parents with a child born with cleft lip and palate is about how they are going to feed their baby. Young ${ }^{35}$ noted that for $95 \%$ of parents issues around feeding were the main concern. It is of paramount importance that feed times are a relaxed and happy occasion for both mother and baby. Therefore one of the most important tasks that the specialist nurses have is to ensure that successful feeding is established as soon as possible after birth, taking into account the mother's preference and any other problems that the baby may have.

In order to do this, a full history of the pregnancy and delivery needs to be taken, a clinical examination of the child performed to determine the general condition of the infant and to exclude any mechanical or neurological problems. Other anomalies need to be highlighted. Children with clefts of the lip and palate are at high risk of having an associated anomaly and there may be cardiac, respiratory and neurological problems which will all have an impact on the appropriateness and safety of feeding.

As a result of the CSAG report ${ }^{1}$ all infants born with a cleft of any type must have a feeding assessment undertaken within the first 24 hours of diagnosis. Ideally this will be within the first day of life. However, in cases of late diagnosis it should be done as soon as possible after referral. Where the diagnosis has been made late, parents are usually very distressed, frequently angry but relieved that the difficulties will be corrected.

Feeding is difficult for babies with CLP because of the altered anatomy within the mouth. In order for feeding to be successful the baby has to do several things. Firstly, the baby has to be able to lift the soft palate to close off the nasal airway from the mouth. Then the tongue has to move forward over the lower gum and cup the nipple or teat. Thirdly the baby must make a seal around the nipple or teat with the lips ${ }^{36,37}$. Whether the baby is breast or bottle-fed, effective feeding depends on tongue 
movement. In a breast-fed baby the tongue ripples along the base of the breast helping to express the milk out of the nipple. In bottle feeding the tongue compresses the teat against the roof of the mouth.

The obvious difficulty these babies have is that they cannot create adequate negative intra-oral pressure to be able to express the milk from the breast or bottle. This pressure, coupled with the rhythmic jaw and tongue movements, is what helps to hold the nipple in place. Added to this is the stabilising effect of the lips. Without the seal the lips should make around the teat, the baby finds it harder to keep the nipple in the correct position. This is not just relevant to those babies with a complete cleft of the lip and palate. Even those with the smallest cleft can have severe difficulties with feeding ${ }^{38}$. The most common problems in the community are prolonged feeding times and an inadequate nutritional intake. In fact, most babies who present late with a diagnosis of cleft palate usually come via the paediatric ward where they are admitted with failure to thrive ${ }^{39}$.

One of the most important things to remember is that feeding times should be a pleasurable experience for both mother and baby. When a mother is struggling to feed a hungry baby and cannot satisfy or pacify her baby this leads to feeding times becoming a frustrating struggle with mother and infant becoming increasingly distressed ${ }^{40,41}$.

It is not always possible to achieve a pleasurable feeding experience when the baby has to be fed by nasogastric tube for whatever reason. One of the most common reasons for a cleft baby being fed this way is due to Pierre Robin sequence. Many of these babies have severe airway problems and due to the smallness of the lower jaw, the tongue remains in a very posterior position, making oral feeding impossible for weeks or even months. With these babies it is important for the parents to feel comfortable and confident with the feeding method. Pleasant oral stimulation should be provided for the baby to avoid oral aversion ${ }^{36}$.

Wherever possible the mother's preference for feeding her baby is taken into consideration. However, there are some feeding protocols professionals have to take into consideration. If a baby has an incomplete cleft of the lip then the mother may feed the baby however she wishes. For a baby who has a cleft palate only, then she has a choice. If she chooses to formula feed, then the specialist nurse will provide soft bottles and demonstrate the assisted feeding technique. If she chooses to breast feed, then support will be given and equipment provided to help with expression of breast milk, and soft bottles with a scoop to use for top up feeds to avoid nipple/teat confusion. Within our service it is only when the baby has a complete cleft of both the lip and palate that soft bottles with a scoop must be used. If the mother wishes to use her own milk then we will provide a breast pump and give all the support and encouragement we can.

\section{Continuing role of the Specialist Nurse}

The role of the Specialist Nurses is not solely confined to the antenatal and postnatal care of the parents and child. They are involved with these families throughout childhood and into adulthood but particularly during the first year of the child's life. This is due to the preparation for surgery, the pre- and post-operative visits and 

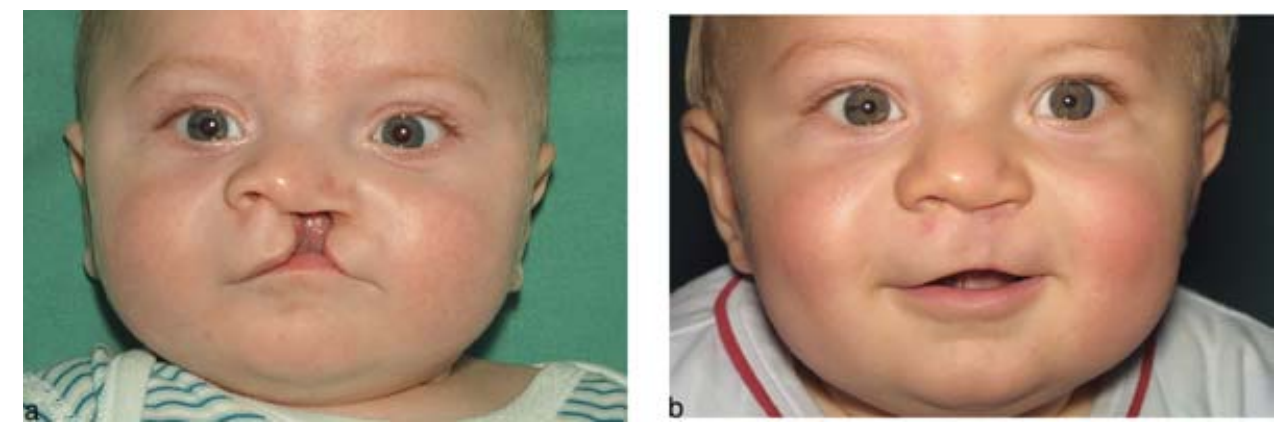

Figure 8 Complete unilateral cleft lip and palate - pre- and post-op views.

the liaison with the primary care team to ensure that the child is in the best physical state for the surgery. Historically, these children often presented in the failure to thrive category but now with specialist centres this is hopefully a thing of the past. Those children who still have faltering growth are being referred to paediatricians at a much earlier stage.

As part of our pre-operative care, nose and throat swabs are taken. At this visit the Specialist Nurse discusses what will happen in hospital, and answers any questions the parents or children may have. Parents are offered a visit to the ward for those who are new to our service, in order to allay fears and to reassure both the parents and the children. It allows the families to visualise ward life thus helping prepare for surgery. Issues of diet and arm splints, and how to care for the wound at home are discussed. These visits are vital as they make admission to hospital less stressful for all concerned.

Once all early surgery is completed, the nurses can withdraw slightly from the care of these children, whilst ensuring that the health visitor is well acquainted with the family and the child's medical history. They continue to give holistic care based on the family's needs, liaising with all members of the primary health care team. Constant contact is maintained with the speech and language therapist, psychologist, and school nurse to ensure they are aware of potential problems such as bullying.

\section{Surgery}

Closure of the cleft in the lip and palate requires a surgical operation. There are a variety of surgical techniques and timings. Any surgical protocol has to satisfy several apparently contradictory requirements

1 Cosmetic restoration of a normal appearance to the baby at an appropriate time.

2 Functional restoration of the lip and particularly the palate to provide normal eating and drinking and produce a functionally adequate palate to allow the development of normal speech. 
3 Optimum facial growth and development to prevent deformity developing in association with impaired growth.

Only a minority of surgeons now practise repair of the lip in the neonatal period. The results of neonatal repair are no better than later surgery and there is no psychological benefit to the parents ${ }^{42}$. In addition neonatal surgery carries inherently higher risk. Most surgeons repair the lip and often the alveolar area and front edge of the hard palate between 3 and 6 months.

The later the closure of the palate, the worse the speech ${ }^{43}$. Even before speech develops, babbling patterns are abnormal in children with cleft palate and many surgeons close the palate at six months or younger. However, surgery to close the alveolus and palate has been linked with poor facial growth. Early closure of the soft palate with delayed closure of the hard palate has been suggested as a compromise but has produced poor speech results ${ }^{44,45}$.

Closure of the cleft in the alveolus and hard palate involves mobilisation of tissues laterally and their displacement across the midline to cover the cleft. Often large raw areas are left to epithelialise. Closure of the soft palate may require extensive dissection of the soft tissues laterally. The scarring produced by many of these manoeuvres has been implicated in the facial deformity of adults with previously repaired clefts and current surgical techniques aim to minimize the growth disturbance.

There is evidence that good facial growth and good speech can be achieved by closure of the hard and soft palate in a single stage before one year of age provided that surgery is as atraumatic as possible ${ }^{1,46}$.

In our centre:

1 Lip repair is performed at 3 months of age. At the same time if the palate is cleft the anterior hard palate and alveolar defect are closed with a single layer flap of mucosa from the vomer.

2 The lip is repaired using a modification of the Millard technique. This allows the short medial lip to lengthen by rotation downwards and advances the lateral element across the lip. It is important to detach the lip muscle from its abnormal attachment to the pyriform margin and reconstruct it anatomically across the lip and into the region of the anterior nasal spine.

3 The resulting scar follows reasonably well the line of the philtrum - Figure 8.

4 The deformity of the nose is corrected by mobilising the underlying cartilages from the overlying skin and mucosa, allowing them to move into a better position as the lip is repaired. The nasal cartilages are supported by sutures within the skin and mucosal envelope.

5 Palate repair is performed at 8 months of age using a single stage technique for combined hard and soft palate closure.

6 Mucoperiosteal flaps are elevated from the hard palate and repaired in the midline.

7 The levator muscle in the soft palate is dissected free from its abnormal attachments to the back of the hard palate and medial margin of the cleft. The muscles from each side are turned posteriorly within the mucosal envelope and repaired to each other toward the posterior end of the palate to recreate the levator sling. 
8 Mucosal releasing incisions are used only where necessary and their length is kept as short as possible.

\section{Hearing}

There is a well-recognised association between cleft palate and middle ear disease that is related to failure of the ventilatory function of the Eustachian tube. There are several reasons for this including:

1 The Eustachian tube is short.

2 The lateral lamina of the tube is deficient causing the lumen to collapse.

3 The tensor veli palatini muscle is abnormally inserted into the tube.

In addition it is important to exclude other causes of deafness in babies with cleft palate.

Eustachian tube dysfunction causes otitis media with effusion (OME), commonly known as glue ear. This is associated with a high incidence of acute otitis media due to secondary infection, tympanic membrane abnormalities including perforations and cholesteatoma. The management of OME involves the use of ventilation tubes inserted through the tympanic membrane under general anaesthetic. In some centres ventilation tubes are inserted early and often repeatedly. In others a watch and wait policy is adopted. Unfortunately the evidence to support either view is not conclusive since repeated ventilation of the ear can result in similar problems to untreated OME.

Palatal surgery improves Eustachian tube function and it is hoped that the earlier surgery now commonly practised will be associated with overall improvement in hearing within the cleft palate population. However, appropriate assessment and follow-up of hearing is vital and other causes of deafness must be excluded. Follow-up every six months of all primary school aged children with cleft palate is recommended.

\section{Speech and Language Therapy}

Children born with a cleft involving the palate are at risk of developing abnormal speech patterns. There is considerable variation in the literature about the number of children with CLP/cleft palate who go on to have speech problems following primary repair of the palate. Spreistersbach et $\mathrm{al}^{47}$ quoted $50 \%$ of children with repaired cleft palate developed normal speech spontaneously, $25 \%$ required speech and language therapy and $25 \%$ required further palatal surgery. Witzel ${ }^{48}$ reported that $25 \%$ developed normal speech spontaneously and $75 \%$ required episodes of speech and language therapy throughout childhood and adolescence. Hall ${ }^{49}$ stated that $80 \%$ of non-syndromic cleft children who had palate repair before 18 months of age did not require speech and language therapy. The CSAG ${ }^{1}$ study audited outcomes of 457 children aged 5 or 12 years who had been treated for unilateral CLP in the UK. Approximately $33 \%$ of 5 year olds and $14 \%$ of 12 year olds presented with 
serious consonant articulation errors. In the normal population 12 year olds have no articulation errors. However, the Eurocleft Speech Study, as reported by Grunwell ${ }^{50}$, found the articulatory performance of 11-14 year olds to be good, suggesting that with increasing age speech patterns of cleft palate individuals tend to converge to the normal.

The aetiology of the speech disorder is often multifactorial and complex in nature with many structural and non-structural factors potentially interacting to cause speech problems. Aetiological factors include ${ }^{51}$ :

1 abnormal oronasal structure and/or function e.g. velopharyngeal insufficiency, nasal airway deviations, hearing and ENT problems, residual clefts and oronasal fistulae.

2 abnormal oronasal structure and growth e.g. dental and occlusal anomalies.

3 abnormal neuromotor development e.g. abnormally learned neuromotor patterns, developmental learning deficits and neurological factors.

4 abnormal or disturbed psychosocial development e.g. impact of physical difference on parents and child.

Following primary palate repair, cleft speech characteristics that are structural in nature are hypernasality, nasal emission and nasal turbulence. These are all features of resonance and occur when the velopharyngeal sphincter does not close adequately, allowing air to escape into the nose during speech. Consonant production errors can also occur when the child tries to compensate for the lack of oral air pressure required for most consonants used in English. Further surgery is usually required to remediate these problems, although speech and language therapy may also be necessary. Hyponasality is also a feature of resonance and occurs when there is insufficient air in the nose during speech. In the cleft population this may occur in the presence of a nasal airway obstruction such as a deviated nasal septum. Dental and occlusal factors related to abnormal structure may give rise to compensatory errors in consonant production.

Cleft type characteristics of a non-structural nature are indicated by articulatory difficulties. Although primary palate repair has provided an adequately functioning soft palate and velopharyngeal sphincter, consonant production has been mislearned perhaps because of poor oromotor stimulation prior to surgery, faulty motor programming, ENT problems, or social factors. Speech and language therapy is required to remediate the resulting speech disorder rather than further surgery.

It is important to recognise that children with CLP/cleft palate may exhibit the same developmental language and articulation disorders as children without a cleft. Approximately $5 \%$ of the normal primary school population have speech and language disorders ${ }^{52}$.

As a key member of the multidisciplinary team it is the role of the Specialist Speech and Language Therapist to monitor and assess speech and language development from birth to completion of treatment (approximately 20 years of age), make differential diagnoses, advise parents/carers, liaise with other team members and provide appropriate and timely intervention. The CSAG Study ${ }^{1}$ found the major input for speech and language therapy was in the first seven years. 
The following outline of speech and language therapy management is cited as good practice $^{53}$.

1 Birth to palate repair

Support and information to parents/carers about the development of communication and how the cleft may affect speech development. Encouraging normal patterns of parent-child interaction.

2 Palate repair to 18 months

Monitoring general communication development and advising parents as appropriate, particularly in relation to emerging babble patterns. At 18 months children will have a routine assessment which looks at play skills, social development, interaction, receptive language, expressive language and consonant production.

318 months to 3 years

Continued monitoring of all aspects of communication with particular regard to velopharyngeal function and consonant production. At 3 years the child will have a more formal assessment of receptive and expressive language skills and an audio and video recorded sample of speech that is analysed in detail.

\section{3 years to 4.5 years}

Monitoring and intervention as required, based on comprehensively analysed speech sound data. Liaison with external agencies, particularly nurseries and education.

5 5, 10, 15 and 20 year audit

Collection and analysis of speech data using audio and video recordings.

\section{Other investigations}

The specialist Speech and Language Therapist with the cleft team will contribute to assessment, diagnosis and treatment planning for children requiring further surgery for velopharyngeal insufficiency affecting speech outcome and symptomatic palatal fistulae. In addition, assessment is required for older children and adults who require maxillary advancement and those needing prosthetic management of velopharyngeal insufficiency where surgery is contraindicated.

7 Speech and Language Therapy Intervention

Intervention can take place at any time but must be appropriate, timely and tailored to the individual.

The aim of the Speech and Language Therapist is to facilitate normal development, prevent problems and help the child with a CLP/cleft palate achieve their optimum communication potential. 


\section{Dento-Facial Development and treatment}

\section{Dental aspects}

During embryological development the primordial dental lamina forms within the maxillary processes due to a proliferation of mesenchymal tissue and an invagination of oral epithelium. This concentric arch shaped band of tissue swells to produce tooth germs, which eventually produce the teeth. This sequence commences at week 7 . In the patient with a cleft this process is disturbed around the cleft site and may result in the duplication of tooth types either side of the cleft, malformed roots and/or crowns, enamel hypoplasia, absence or ectopia of teeth ${ }^{54}$. Msx1 genes that are thought to be related to clefting are also aberrant in the non-cleft population who have hypodontia (absent teeth) and consequently patients with clefts may have missing or aberrant teeth distant from the cleft in either jaw. Children with clefts are found to suffer higher levels of decay than non-cleft siblings, which may be genetic or environmental. This further mutilation of their dentition can cause problems with future alveolar bone grafting, orthodontics, complex cosmetic/restorative dentistry and orthognathic surgery, as outlined below.

\section{Orthodontics}

Orthodontic treatment (alignment of the teeth and their underlying supporting structures) can be used to intervene at almost any age from birth to teenage years, but the orthodontic cleft specialist must be cognisant of the burden of care for these patients and ideally treatment should be limited to discrete episodes of treatment that contribute to the end result e.g.:

1 Pre-surgical dento-facial orthopaedics - use of a dental plate to align the maxillary segments prior to initial lip and palate repair (from birth).

2 Preparation for alveolar bone grafting (7+ years) - see below.

3 Align the maxillary dentition (usually using fixed appliances) in the growing child if the appearance causes the child distress or the irregular teeth are traumatising soft tissues (6+ years).

4 Align maxillary and mandibular teeth in the teenager using fixed appliances (12+ years).

5 Prepare for orthognathic surgery using fixed appliances and to detail the occlusion post-operatively (adult).

6 Fabrication of palatal lift appliances for patients with velo-pharyngeal dysfunction. The poorly functioning soft palate is raised and the velo-pharyngeal space obturated to reduce hypernasal speech which assists the Speech and Language Therapist in cases that are otherwise untreatable by language therapy alone with/without surgery. 


\section{Alveolar bone grafting}

Despite early soft tissue repair around the cleft lip and palate, the bony segments of the maxilla and premaxilla are separate. This produces poor alignment, with the maxillary segments collapsing mesio-palataly, behind the premaxilla, which may be particularly severe in the bilateral cleft. The aim of alveolar bone grafting is to reconstruct the bony defect and replace absent alveolar (tooth bearing) bone. At the age of 7-8 years the roots of the canine teeth are half formed and at this point the maxillary segments can be expanded over many months using fixed orthodontic appliances which reposition the maxillary segments into the 'ideal arch form'. This is planned to be complete by 9-11 years of age. The arch is held rigidly with orthodontic fixation in the palate and on the buccal surfaces of the teeth, allowing the defect to be opened surgically. A graft of iliac crest cancellous bone is packed into a mucoperiosteal pocket to the full extent of the defect, often with a degree of overcorrection beneath the nasal ala. This fuses the maxilla, provides alar base support, and allows the unerupted canine tooth to erupt through the graft inducing further bony consolidation ${ }^{55}$. Bilateral clefts are (ideally) grafted simultaneously. Teenage patients usually need further complex orthodontics to straighten the maxillary dentition as it erupts and deal with absent and aberrant teeth. Adults with significantly disturbed jaw relationships may undergo orthodontics combined with orthognathic surgery after completion of facial growth.

\section{Facial growth}

In unilateral clefts there is an asymmetry of the premaxilla (which is tilted up toward the cleft side), and a deviation of the nasal septum (which bulges towards the cleft side). In bilateral clefts the premaxilla occupies an anterior position on the underside of the nasal septum. These features are evident from an early embryological stage ${ }^{56,57}$ and it has been suggested that this may be due to an increased growth rate of the tongue or nasal septum. Fetuses with clefts also demonstrate altered tongue positioning, muscular activity and swallow patterns, which contributes to a variable distortion of the maxillary and premaxillary segments. The width of the cleft at birth may be extremely variable between individuals. Total fetal development of the maxillary arch may be deficient, but research is contradictory. Post partum, antero-posterior facial growth in patients with clefts of the lip and alveolus is within normal range, relative to the cranial base ${ }^{58}$ although as with all cleft types there is an increased inter-occular distance ${ }^{59}$. Facial growth differs further in individuals with cleft palate, with a reduction in the degree of forward growth (relative to the cranial base) of the maxilla particularly but also the mandible ${ }^{59,60}$. This may be a feature of clefting or a consequence of their early surgery ${ }^{61}$. Lower face heights are increased compared to non-cleft individuals ${ }^{59}$. In the fully-grown patient these skeletal discrepancies may warrant further orthodontics (in the region of 2-3 years of treatment) and orthognathic surgery to reposition the jaws into a more aesthetic position. Advancement of the 
maxilla may jeopardize velo-pharyngeal function, and sometimes a compromise must be reached between appearance and function.

\section{LONG-TERM MANAGEMENT}

It is easy to concentrate upon the physical aspects of this problem. However, the longterm psychological management of a child with a cleft lip and/or palate continues to be important at all levels of the service. For example, clinics are as psychologically minded as is possible. Asking about the emotional life and adjustment of the child and family as a matter of routine can help to normalise psychological approaches to care. In addition, providing toys that are developmentally appropriate to the needs of the children visiting the clinic, can give the message that the child as a whole has been thought about carefully before their visit. It is also important to include the child in the consultation process as far as possible.

The Newcastle team feel that providing information (written or other) about who the team are, their different roles and some of the concerns which can be raised by parents, e.g. normal development and teasing, is important in the long-term care of children and their families. Such questions and concerns can often be addressed by giving families information about other relevant services which they are able to utilise without further intervention from the team. This approach can be both empowering for families and efficient in terms of time for families and services.

Some concerns families present with cannot be adequately addressed by lowerlevel psychological approaches and may require a psychologist working alongside another team member to inform their practice, or a referral to the clinical psychologist for individual, group or family work. Some examples of such concerns include: low self-esteem, underachievement, body image, managing the reactions of others, surgical preparation, needle phobia, expectations/hopes, bullying, or behavioural problems related to frustration at not being understood by others due to speech difficulties.

Taking a psychological approach to care does not have to involve a psychologist; all members of the cleft team should incorporate a psychosocial perspective into their care of patients with cleft lip and/or palate.

\section{BACKGROUND TO THE RECENT CHANGES IN CONFIGURATION OF CLEFT CARE IN THE UK}

In the light of published work, professionals in the field of cleft work expressed concern regarding the quality of treatment for patients with CLP in the UK ${ }^{62,63}$. In 1995 the Department of Health in the UK charged the Clinical Standards Advisory Group to investigate the quality of care within the $\mathrm{UK}^{64}$. All children in the UK with a unilateral complete CLP aged 5 or 12 years of age in 1996-1997 were examined. Their speech, hearing, appearance, dental malocclusion, dental health, quality of bone graft (12y) and 
skeletal base relationships were examined. The study found that the average result in all these areas was poor. Fifty seven centres provided cleft care with a paucity of good clinical records. The volume of surgery carried out by each surgeon was variable, with an average of 6 cases per year ${ }^{64}$. Bone graft quality and dental and skeletal base relationships were also compared with a European study by six European centres at 8-10 years of age. Children from the UK were more likely to suffer mid face retrusion and poor dental relationships than three of the European centres. Fewer than $60 \%$ of children in the UK had a successful bone graft in comparison with $97 \%$ from one of the other European centres ${ }^{63}$. It was therefore clear that some patients might not have been receiving optimal care in the UK.

The CSAG made several recommendations ${ }^{1}$, including,

1 Expertise should be limited to 6-15 centres in the UK.

2 Each centre should provide a full range of cleft care.

3 Documentation must be improved, including a nationwide database.

4 Results should be regularly audited allowing comparisons between centres.

5 Training should be provided for specialists in cleft care in high volume centres only.

So far in the UK, 10 centres have been identified and teams of experts are being recruited. Each clinical team consists of specialist orthodontists, surgeons, speech and language therapists, specialist nurses, geneticists, paediatricians, ENT specialists, anaesthetists and psychologists. In addition they have support staff responsible for data collection, audit documentation and photography. The teams devise and work to strict protocols covering all aspects of care, based where possible on a sound clinical evidence base. Actual delivery of care varies between the 10 centres dependant upon the geography and the demographics of a region.

\section{Note}

The Cleft Lip and Palate Association (CLAPA) can be contacted at CLAPA Head Office, 1st Floor, Green Man Tower, 332B Goswell Road, London EC1V 7LQ.

The Newcastle part of the Northern and Yorkshire Cleft Lip and Palate Service is based at:-

The Royal Victoria Infirmary

Queen Victoria Road

Newcastle upon Tyne

NE1 4LP

\section{Acknowledgements}

The authors wish to thank Stella Dickinson and Catriona Morley for their major contribution to the production of this paper. 


\section{REFERENCES}

1 Clinical Standards Advisory Group (CSAG). Cleft lip and/or palate. Report of a CSAG Committee. The Stationery Office, London, 1998.

2 Bender PL. Genetics of cleft lip and palate. J Pediat Nurs 2000; 15: 242-49.

3 Abyholm FE. Cleft lip and palate in Norway. Registration, incidence and early mortality of infants with CLP. Scand J Plast Reconstr Surg 1978; 19: 295-300.

4 Jensen BL, Kreibord S, Dahl E, Fogh-Anderson P. Cleft lip and palate in Denmark 1976-1981: epidemiology, variability and early somatic development. Cleft Palate J 1988; 25: 258-69.

5 Fogh-Anderson P. Inheritance of harelip and cleft palate. Domus Biologiae Hereditariae Humanae, Copenhagen, University of Copenhagen, 1942.

6 Gregg TD, Boyd D, Richardson A. The incidence of cleft lip and palate in Northern Ireland from 1980-1990. Br J Orthod 1994; 21: 387-92.

7 Amaratunga NA. A study of etiologic factors for cleft lip and plate in Sri Lanka. J Oral Maxillofac Surg 1989; 47: 7-10.

8 Millerad J, Larson O, Hagberg C, Ideberg M. Associated malformations in infants with cleft lip and palate: a prespective population-based study. Pediatrics 1997; 100: 180-86.

9 Stoll C, Alembik Y, Dott B, Roth MP. Associated malformations in cases with oral clefts. Cleft palate Craniofac J 2000; 37: 41-47.

10 Hagberg C, Larson O, Millerad J. Incidence of cleft lip and palate and issues of additional congenital malformations. Cleft Palate Craniofac J 1998; 35: 40-45.

11 Lees M. Genetics of cleft lip and palate. Watson ACH, Sell DA and Grunwell P (eds) Management of Cleft Lip and Palate. London: Whurr Publishers; 2001: 87-104.

12 Christensen K, Joel K, Herskind AM, Murray JC. Long-term follow up study of survival associated with cleft lip and palate at birth. Br Med J 2004; 328: 1405.

13 Kernahan DA.The Striped Y - a symbolic classification for cleft lip and palate. Plast Reconstr Surg 1971; 47: 469-70.

14 Royal College of Surgeons, England 1995.

15 Jones MC. Pre-natal diagnosis of cleft lip and palate: detection rates, accuracy of ultrasonography and strategies for counselling. Cleft Palate-Craniofac J 2002; 39: 169-73.

16 Martin V, Bannister P. Cleft care: a practical guide for health professionals on cleft lip and/or palate. APS Publishing, 2004.

17 National Statistics 1998

18 Martin V. Helping parents cope. Nursing Times 1995; 91: 38-44.

19 Zebrowitz L. Reading faces. Window to the Soul. Westview Press, Colorado 1997.

20 Lefebvre A, Barclay S. Psychosocial impact of craniofacial deformities before and after reconstructive surgery. Can J Psychiatry 1982; 27: 579-84.

21 Robinson E. Psychological research on visible differences in adults. In: Lansdown $R$, Rumsey N, Bradbury E, Carr T, Partridge J (eds). Visibly Different: Coping with disfigurement. Oxford, Butterworth-Heinemann 1997.

22 Walters E. Problems faced by children and families living with visible differences. In:Lansdown R, Rumsey N, Bradbury E, Carr T, Partridge J (eds) Visibly Different: Coping with disfigurement. Oxford, Butterworth-Heinemann 1997.

23 Slifer K, Beck M, Amari A, Diver T, Hilley L, Kane A et al. Self-concept and satisfaction with physical appearance in youth with and without oral clefts. Children's Health Care 2003; 32: 81-101.

24 Herskind A, Christensen K, Juel K, Fogh-Anderson P. Cleft lip: a risk factor for suicide. (abstract). 7th International congress on cleft palate and related craniofacial abnormalities, Australia, 1993; 156.

25 Ainsworth M, Bowlby J. An ethnological approach to personality development. Am Psychol 1991; 46: $331-41$ 
26 Righetti-Veltema M, Manzano J. Impact of postpartum depressive symptoms on mother and her 18 month old infant. Eur Child Adolesc Psychiatry 2003; 12: 75-83.

27 Huth-Bocks A, Levendosky A, von Eye A. The impact of maternal characteristics and contextual variables on infant-mother attachment. Child Dev 2004; 75: 480-96.

28 O'Leary J. Grief and its impact on prenatal attachment in the subsequent pregnancy. Arch Women's Mental Health 2004; 7: 7-18.

29 Burgess K, Marshall P, Rubin K. Infant attachment and temperament as predictors of subsequent externalising problems and cardiac physiology. J Child Psychol Psychiatry 2003; 44: 819-31.

30 Langlois J. Infant attractiveness predicts maternal behaviors and attitudes. Dev Psychol 1995; 31: 464-72.

31 Pruzinsky T. Social and psychological effects of major craniofacial deformity. Cleft Palate-Craniofac J 1992; 29: 578-84.

32 Coy K, Spelz M, Jones K. Facial appearance and attachment in infants with orofacial clefts: a replication. Cleft Palate-Craniofac I 2002; 39: 66-72.

33 Pelchat D, Bisson J, Bois C, Saucier J. The effects of early relational antecedents and other factors on the parental sensitivity of mothers and fathers. Inf Child Dev 2003; 12: 27-51.

34 Strauss R, Sharp M, Lorch S. Physicians and the communication of "bad news" - parents experience of being informed of their child's cleft lip/palate. Presentation to the Annual Meeting of the American Cleft Palate- Craniofacial Association. Pittsburgh, April 23rd, 1993.

35 Young J. What information do parents of newborns with cleft lip and palate want to know? Pediatrics 2001; 38: 55-88.

36 Arvedson JC, Brodsky L. Pediatric swallowing and feeding assessment and management. London: Whurr Publishers; 1993.

37 Morris S, Klein DM. Pre-feeding skills (2nd edition). USA, Harcourt Health Services Therapy Skill Builders, 2000.

38 Wolf LS, Glass RP. Feeding and swallowing disorders in infancy, assessment and management. Arizona, Therapy Skill Builders, 1999.

39 Ranalli PN, Mazaheri M. Height weight growth of cleft children birth-6 years. Cleft Palate J 1975; 12: 400-404.

40 Blancuzzo M. Yes infants with clefts can breast feed. Awohonn Lifelines 1998; 2: 45-49.

41 Bowlby AJ. The making and breaking of affectional bonds. London, Tavistock Routledge, 1979.

42 Slade P, Emerson DJM, Freedlander E. A longitudinal comparison of the psychological impact on mothers of neonatal and 3 month repair of cleft lip. Br J Plast Surg 1999; 52: 1-5.

43 Sell D. Speech in Sri Lankan cleft palate subjects with delayed palatoplasty. Unpublished PhD, De Montford University 1992.

44 Bardach J, Morris HL, Olin WH. Late results of primary veloplasty: the Marburg project. Plastic Reconstr Surg 1996; 73: 207-15.

45 Witzel MA, Salyer KE, Ross RB. Delayed hard palate closure: the philosophy revisited. Cleft Palate J 1984; 21: 263-69.

46 Sommerlad BC, Hay NHI, Moss JP. Transactions of the 8th International Congress on Cleft Palate and Related Craniofacial Anomalies. Singapore 1997.

47 Spreistersbach DC, Dickson DR, Fraser FC, Horowitz SL, McWilliams BJ, Paradise J et al. Clinical research in cleft lip and palate: the state of the art. Cleft Palate J 1973; 10: 113-65.

48 Witzel MA. Speech evaluation and treatment. Oral Maxillofac Surg Clin North Am 1991; 3: 501-16.

49 Hall C, Golding-Kushner KJ. Long term follow up of 500 patients after palate repair performed prior to 18 months of age. Paper presented to Sixth International Congress on Cleft Palate and Related Craniofacial Anomalies, Jerusalem, Israel 1989.

50 Grunwell P. The Eurocleft Speech Project: an outline of the results. Paper presented at Royal College of Speech and Language Therapist's Annual Conference 1995. 
51 Grunwell P, Sell DA. Management of Cleft Lip and Palate. London; Whurr Publishing, 2001:

52 Fox VA, Dodd B, Howard D. Risk factors for speech disorders in children. Int I Lang Commun Dis 2002; 37: 117-31.

53 Russell VJ, Harding A. Management of Cleft Lip and Palate. London, Whurr Publishing 2001.

54 Bohn A. Dental anomalies in harelip and cleft palate. Acta Odontol Scand 1963; 21: 1-109.

55 Bergland O, Semb G, Abyholm F. Elimination of residual alveolar cleft. Cleft Palate J 1986; 1: 175-205.

56 Latham RA. Pathogenesis of the skeletal deformity associated with unilateral cleft lip and palate. Cleft Palate I 1969; 6: 404-14.

57 Latham RA. Development and structure of the primary deformity in bilateral cleft lip and palate. Br J Plast Surg 1973; 26: 1-11.

58 Friede H, Figueroa AA, Naegele ML, Gould HJ, Kay CN, Aduss H et al. Craniofacial growth data for cleft lip patients infancy to 6 years of age: potential applications. Am J Orthodont 1986; 90: 388-409.

59 Semb G. A study of facial growth in patients with unilateral cleft lip and palate treated by the Oslo CLP team. Cleft Palate Craniofac J 1991; 28: 1-21.

60 Bishara SE, Iverson WW. Cephalometric comparisons on the cranial base and face in individuals with isolated clefts of the palate. Cleft Palate I 1974; 11: 162-75.

61 Normando ADC, da Silva OG Jr, Capelozza L. Influence of surgery on maxillary growth in cleft lip and/or palate patients. J Craniomaxillofac Surg 1992; 20: 111-18.

62 Mars M, Houston WJ. A preliminary study of facial growth and morphology in unoperated male unilateral cleft lip and palate subjects at 13 years of age. Cleft Palate J 1990; 27: 7-10.

63 Shaw WC, Murray JJ, Sell D, Murphy T, Mildinhall S, Bearn D et al. A six centre European international study of treatment outcome in patients with clefts of the lip and palate. Parts 1-5. Cleft Palate Craniofac J 1992; 29: 393-18.

64 Bearn D, Mildinhall S, Murphy T, Murray JJ, Sell D, Shaw WC et al. Cleft lip and palate care in the United Kingdom - the clinical standards advisory group study: Part 4 Outcome comparisons, training and conclusions. Cleft Palate Craniofac I 2001; 38: 38-43. 